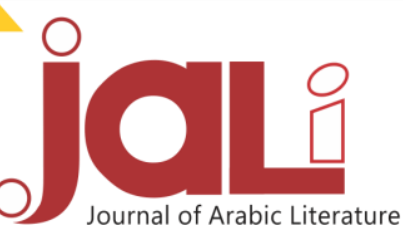

DOI $: \underline{10.1886 / j a l i . v 1 i 2.8447}$

ISSN : 2722-5585

Vol. I-2

\author{
ضالاع الخرافة على التربية في العصر العباسي \\ Hasan Basri, Syarifah, Ali Susanto, Wildana Wargadinata \\ Universitas Islam Negeri Maulana Malik Ibrahim Malang \\ Email:15310138@student.uin-malang.ac.id14721045@student.uin- \\ malang.ac.id14721046@student.uin-malang.ac.idWildana@bsa.uin-malang.ac.id
}

\begin{abstract}
Although the establishment of Abbasid Dynasty was based on bloodshed, the dynasty had experienced golden periods, and one of them was education. That phenomenon was marked by the rise of Baitul Hikmah library which was the meeting point of sciences either from the west (Greece) or the east (India, Persia, and China). Then, Muslim experts developed them into various sciences, such as mathematics, philosophy, astronomy, medicine, physics, metaphysics, and literature. This article aimed to describe forms of fable in Abbasid dynasty, and the impact of fable in education during Abbasid dynasty. This study employed descriptive qualitative method by literature review approach based on post-positivism philosophy. In collecting the data, the study uses various techniques, such as reading and writing. To test the validity of the data, the author applied triangulation method. The data were analyzed through data reduction, data display, and conclusion. The results of this research showed that the fable forms in Abbasid dynasty are fable translation, while the impact of fable to education in Abbasid dynasty is moral learning effort of Abbasid dynasty's society.
\end{abstract}

Keyword: abbasid, education, fable, literature

Corresponding Author: 15310138@student.uin-malang.ac.id14721045@student.uinmalang.ac.id14721046@student.uin-malang.ac.idWildana@bsa.uin-malang.ac.id 
الأيام الأولى من السلالة العباسية، كانت

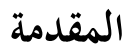

هناك تطورات مثيرة للاهتمام في خضم

المجتمع المحتل، وخاصة بيرسا. تحدف الحركة

كان العصر العباسي إمبراطوري

إلى معارضة التفوق الذي يطالب به به بـان

إسلامي تأسس في ب ا I هـ إلى 707 هـ المسلمون من أصل عربي.

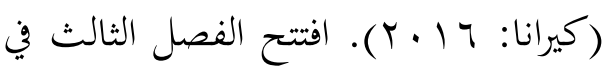

دعت الحركة نفسها سيوبية (القومية)

الدراما الكبرى للسياسة الإسلامية بدور مهم

المأخوذة من مفردات القرآن وتمدف إلى

لعبه الخليفة أبو العباس. أصبح العراق المسرح

غرس روح الأخوة والمساواة بين جميع

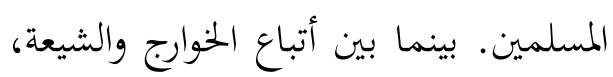

لهذه الدراما العظيمة. في خطبة التتويج التي

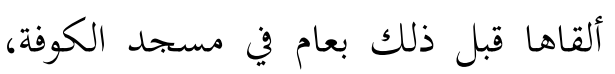
اتخذت الحركة شكلاً سياسياً، بين الفرس التي لئي أطلق الخليفة العباسية الأولى على نفسه بتحست في شكل ديني ينطوي على البدعة الصفح، قسم الدم، الذي أصبح لاحقًا

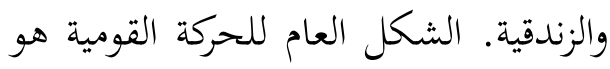
لقبه.

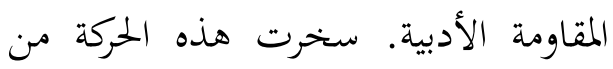

يعتبر اللقب علامة سيئة، لأن هذه

مزاعم العرب حول تفوقهم الفكري، وادعت السلالة الناشئة تشير إلى أغا تعطي الأولوية تفوق غير العرب في بحالات الشعر والسطرة. للقوة في تنفيذ سياساتا. لأول مرة في تاريخ قادت هذه الحركة الأدبية غير العربية شخصيات مثل البيروني وحمزة الأصفهاني،

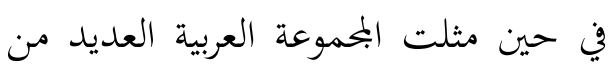

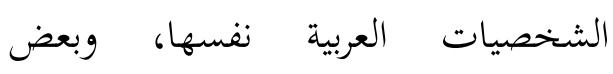
الشخصيات الفارسية، مثل الجاحز وابن

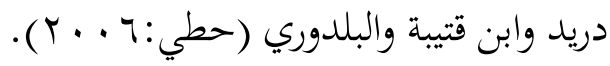
لذا فليس من المستغرب أن بيت ولن الحكمة هي واحدة من المؤسسات الرئيسية لدخول الأدب الأجنبي الذي ترجم إلى اللغة الإسلام، على جانب عرش الخليفة وضع سجادة تستخدم كمكان للإعدام. أصبح الصفح مؤسس السلالة العربية الإسلامية الثالثة - بعد خلفاء الراشدين والعصر الأموي - التي كانت كبيرة جدًا وطويلة العمر (حطي: ب . . ب). ولكن على الرغم من أن إنشاء هذه

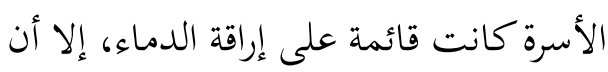
الخلافة العباسية شهدت فترة ذهبية. في 
أجراها الباحثون السابقون تتعلق بهذا الموضوع، الإعداد هو دراسة بعنوان الفن

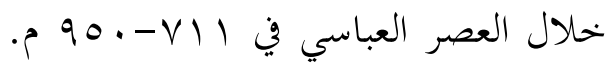
تمدف هذه الدراسة إلى تحديد تطور الفن خلال العصر العباسي، مع شرح الثقافة المادية للفنون الدقيقة التي نشأت من الأسرة العباسية. في الإجابة على الأسئلة، هناك

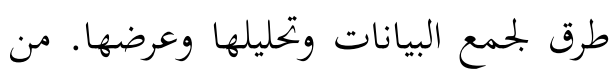
البحث الذي تم إجراؤه، وجد أن أحد أوجه

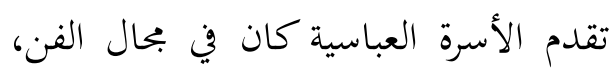

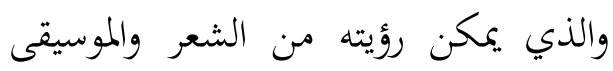
والهندسة المعمارية و والخط (هاريمورتي:

$$
\cdot(r \cdot 10
$$

والبحث الذي أجراه صفطري بعنوان تقدم المسلمين في حالة بني عباسية دراسة حالة: التقدم في بحال العلوم في عصر هارون

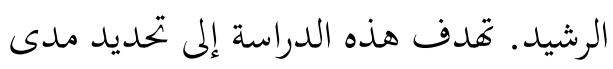
تقدم المسلمين خلال عهد بني عباسية في محال العلوم في زمن هارون الرشيد باستخدام المنهج التاريخي للإجابة على سؤال عن كيفية التعليم في زمن خلافة هارون الرشيد وما تطور التعليم في ذلك الوقت. أما المنهجية

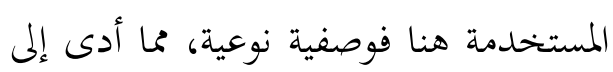
تقدم تعليم بني العباسيين خلال هارون
العربية ويعتبر جسرا رئيسيا في نقل المعرفة. لهذا السبب يُعرف هذا العصر بالعصر

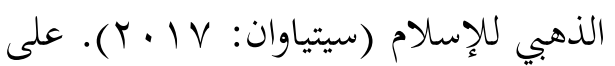
الرغم من أن بيت الحكمة كان في البداية مجرد مكتبة، إلا أن بيت الحكمة لم مئ يكن

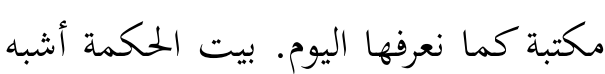
بالجامعة (سيتياوان: V V · ب). أصبح بيت الحكمة مركزًا لاجتماع العلوم من الغرب (اليونان) ومن الشرق (الهند وبلاد فارس والصين) التي تم تطويرها لاحقًا من قبل علماء المسلمين إلى علوم مختلفة، مثل الرياضيات والفلسفة والفلك والطب والفيزياء والميتافيزيقيا، وكذلك ولات ولأدب

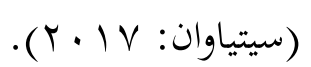
خاصة في بحال الأدب، الخرافات لها مكانا الخاص بها. لم تكن الأعمال الأدبية التي ليست فقط دليلاً ملموسًا على تقدم

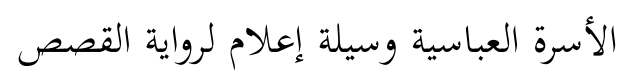

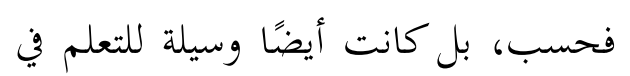
ذلك الوقت. من الخرافات التي اشتهرت في ذلك الوقت كانت كليلة ودمنة التي كانت ترجمات من اللغات الهندية. بناءً على المواقع التي يبحث عنها الباحثون، هناك العديد من الدراسات التي لئي لئي 
الرشيد من خلال تقديم المنح الدراسية ستفحص هذه الدراسة شكل الخرافات والنهوض بالمكتبة، وتأسيس بيت الحكمة خلال العصر العباسية وأثرها في بحال التربية وترجمة الكتب العلمية إلى اللغة العربية. خلال العصر العباسي. حدث تقدم في التعليم في هذا الوقت بسرعة

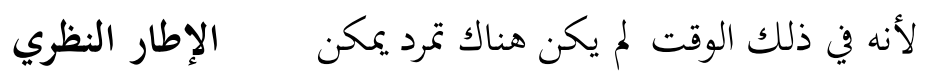
أن يعطل عملية التطور التربوي، والعلوم التي تعريف الخرافة لغة لغن تطورت في ذلك الوقت وهي العلوم ارتبط لفظ "الخرافة" بهكاية الحيوان في

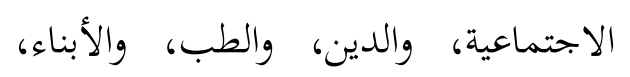

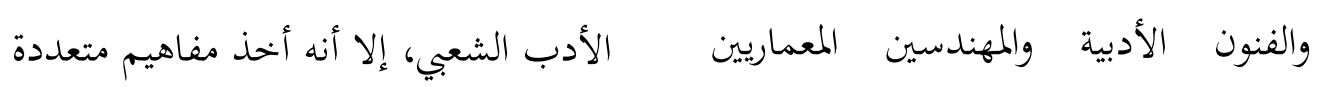

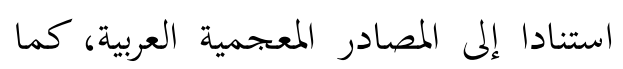
.$(r \cdot 10)$

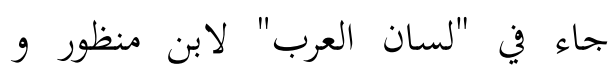

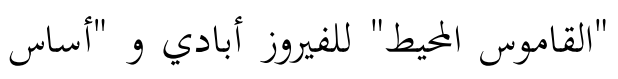

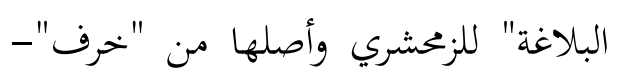

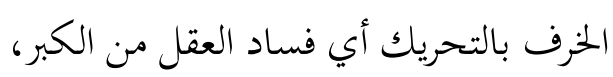
وقد خرف الرجل بالكسر (خرف) يخرِف

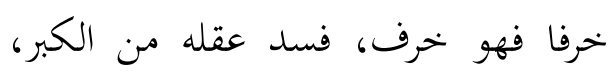

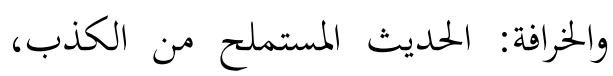
وقالو "حديث خرافة". ذكر ابن الكلبي في قولم حديث خحافة أن خرافة رجل من عذرة اختطفته الجن تم رجع إلى قومه فكان يحدث

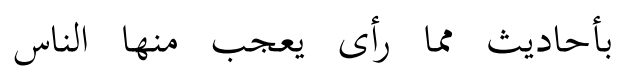
فكذبوه، فجرى على السن الناس (بهيجة:

$$
\text { . (r. I T/r.11) }
$$

أحد الباحثين الذين درسوا أيضا دراسة هذا الخرافة كان نور الحق بعنوان كتاب نشر وتنمية المعرفة والدعوة في عملية الحضارة الإسلامية الكلاسيكية. تستخدم

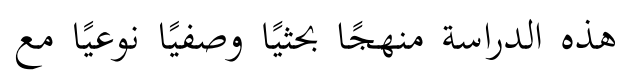
نتائج الدراسة بأن نشر الكتب يوسع المعنى باعتباره عملية حضارية ودعاية عالمية في العلوم، حيث يمتد نشر الكتب ليس فقط للمجتمع المسلم والعالم الإسلامي، ولكن له له

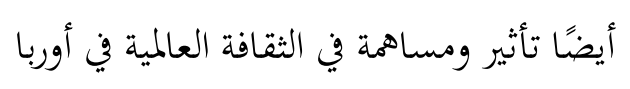
المعاصر. من شرح البيانات أعلاه، يمكن الاستنتاج أن دراسة دور الخرافة خلال الأسرة العباسية في عالم التعليم لم يتم القيام بها قط. لذلك 
الإجتماعية والإقتصادية والتي تعطينا تمثيلا لما يجري في المجتمع الإنساني وهذا النوع من القصص ليس بحديث العهد، بل تمتد جذوره

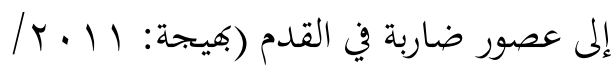
. ( T. I T

\section{هيكل خرافة}

الهياكل في الخرافات على النحو

$$
\text { التالي (فاتن وآخرون: 1 1 • ب). }
$$

التوجيه، يجب أن يحتوي على مقدمة

الشخصية وتحديد الأحداث. ثم المضاعفات

والمراد هنا تحتوي على مشاكل بالأرقام. ثم القرار يعني يحتوي على حل المشكلات. ثم الرمز (غير مطلوب). المراد هنا يحتوي هذا الرمز على التغييرات التي تحدث في الشخصية الشردية للأفضل والنصائح أو الدروس التي يمكن التين أخذها من القصة.

\section{أشكال مختلفة من الخرافات}

عند النظر من وقت ظهورها، تنقسم الخرافات إلى نوعين وهما الخزافة الكلاسيكية. شكل الخزافة في هذا النوع هو الئر قصة موجودة في العصور القديمة وغير معروفة في أي وقت. يتم نقل القصص في هذه
تعريفها اصطلاحا

تنقسم قصص الحيوان في جانبها الفني

الى شعرية ونثرية أما من موضوعها فيمكن لفميون حصر ها في التعريفات التالية (كيجة: $:(r \cdot) r / r \cdot 1)$

قصص الحيوانات المحافظة على صفاتما

الحيوانية، تحاول الشرح وتعليل طباعها وأشكالها فهي قصص تعليمية، علمية في أحيان أخرى غالبا ما تدخل في أطار أدب فئسئ

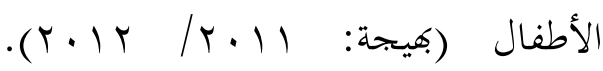
قصص الحيوانات المتقمصة لشخصية الإنسان تأخذ الطابع الرمزي التعليمي في التعبير عن قضايا اجتماعية واخلاقية تربوية في الوسط البشرى الاجتماعي. والتعريف الثاني هو الذي نقصده في التعريف الاصطلاحي للخرافة أو ما تعرف هون لنديف

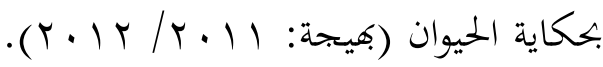
فهي فرع من فروع الحكاية الشعبية التي تضم إلى جانب حكايات أخرى كحكايات الواقع الاجتماعي والحكايات الهزلية وحكاية الواقع الأخلاقي وحكايات الألغاز (كيجة:

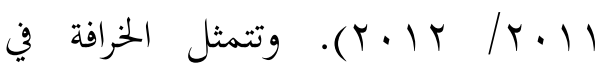

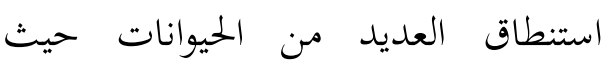
نستعلمها كرموز لتصوير بعض الوقائع 
الخرافة الكلاسيكية أو إخبارها من قبل الآباء طرق مختلفة في أبحاثهم. لذلك استخدم

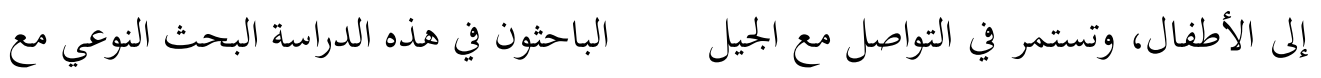

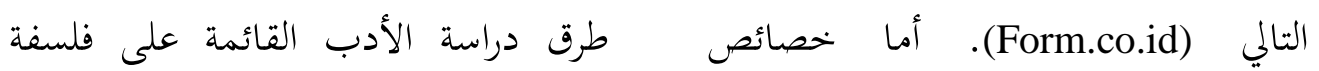

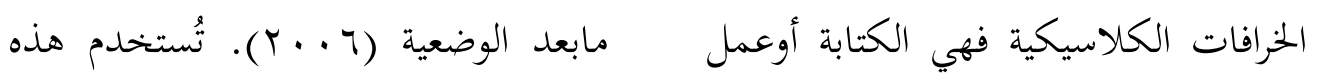
القصص القصيرة. ويتم صنع باستخدام الطريقة لدراسة الظروف الطبيعية للأشياء، موضوع بسيط. ثم لديها رسالة أخلاقية حيث يعمل الباحثون كأدوات رئيسية. بينما سميكة. والأخر لايزال تصوير الشخصيات تم أخذ عينات من مصادر البيانات عمدا.

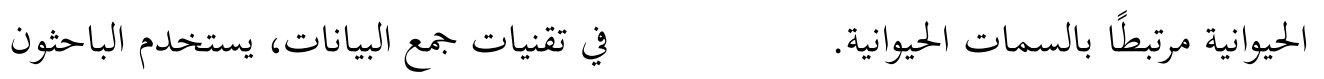
والنوع الثاني الخرافة الحديثة. شكل العديد من التقنيات وهي: قراءة وتسجيل. لاختبار صحة البيانات، استخدم الخزافات في هذا النوع هو قصة تم إنشاؤها في وقت قصير نسبيًا وصنعها المؤلف عمدا

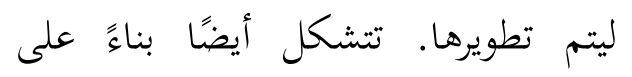
الأحداث التي تحدث في حياة الإنسان (rumus.co.id) الحديثة فالكتابة أوالاستفادة من القصص المتنوعة (الطويلة أو القصيرة). ويتم البناء باستخدام مواضيع ليست بسيطة (معقدة).

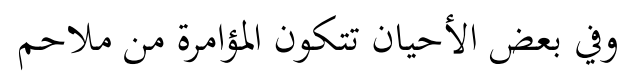
أو قصص. وشخصيتها الفريدة. اللذين قالا أن الأنشطة في تحليل بيانات البحث النوعي تم تنفيذها بشكل تفاعلي، واستمرت بشكل مستمر حتى تم تشبع البيانات. الأنشطة في تحليل البيانات، أي تخفيض البيانات، عرض البيانات، رسم الاستنتاج/ التحقق (سوغيونو: م · . ب).

\section{ضلاع الخرافة على التربية في العصر العباسي 87}


Vol. I-2

يعتمد وجود خرافة الترجمة على

حب الخليفة للعلوم. أطلق عليه الخليفة نتائج البحث و مناقشتة المنصور الذي نظر إلى المعرفة العلمية الدينية والعالمية بطريقة متوازنة. خاصة اهتمام أما نتائج البحث مناقشته في هذه الدراسة على النحو التالي؛ المنصور للمنح الدراسية العالمية هو توفير إعانات كبيرة يقدمها لترجمة كتب مختلفة عن شكل الخرافات في العصر العباسية. العلوم من مختلف التخصصات من اللغات كانت العباسية مثل العرب بشكل اليونانية والهندية. استمر شغف المنصور وحبه عام تخظى بتقدير كبير لشيء ذاتي خاص، للعلوم من قبل أبنائه وأحفاده الذين أصبحوا

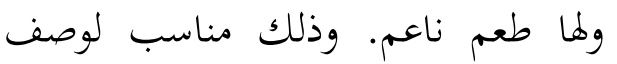
الخلفاء بعده. إهمم يحترمون المترجمين تقديراً الفن. في ذلك الوقت، طور الخليفة أنواعًا

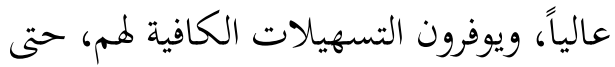
مختلفة من الفنون، وخاصة الأدب بشكل تتمكن حركة الترجمة من العمل بسلاسة.

تأثير الخرافات في التربية خلال العصر

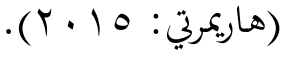

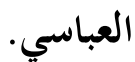

من الدراسات التي أجريت، وجد

واحدة من الكتب الجيدة التي تمت

الباحثون خرافة كانت استثنائية خلال هذه ترجمتها بنجاح في ذلك الوقت كانت خرافات كليلة ودمنة التي نشأت من الهند ثم السلالة. وهي خرافات كليلة ودمنة. يحتوي تم إحضارها إلى بلاد فارس في عهد هذه الخرافة على موضوعات رئيسية تدور

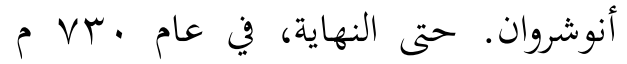
حول احتياجات البشر في حياتهم، مثل كتبت الخرافة الترجمية للطبعة الفارسية التي الالتزام بالابتعاد عن سماع كلام لا معنى له، ترجمت إلى العربية من قبل عبد الله بن المقفع. ومما يوحي بإهاء الجريمة، وفوائد الصداقة، تم يمكن استنتاج أن شكل الخرافة خلال وسر النسيان، وخطر التسرع وفوائد التحلي العصر العباسية كان خرافة الترجمة بالصبر، وحظر التمسك بمن لديهم الرغبة

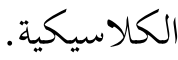


وهكذا، وصمة العار أمام الشعب، والتحرر باحترام الآخرين، والتعاليم الأخرى ذات من الاستبداد، والوحدة لتقويض السلطة، الطابع النبيل المفيدة في تكوين الشخصية. الخرافات خلال هذا العصر مليئة

$$
\text { وقيم الخير والفضيلة بوريادي: } 9 \text {. . ب). }
$$

أيضًا بالقيم الأخلاقية التي تعتبر مهمة جدًا

وبكسب مأمون بن محي الدين للتطور الروحي لأجيال من العصر العباسي. الجنان (في بوريادي)، فإن قصة الكليلة كمثل قيمة الوحدة وقيمة الحقيقة وقيمة والدمنة هي قصة قصيرة تروي حياة القداسة وقيمة العدل وقيمة الحكمة وقيمة

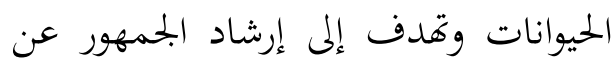
الحلكمة والقدوة، وبنقذ ابنه حيث يتم الواقع والمعرفة وقيمة الشجاعة وقيمة الحب إدخال العديد من مشاكل قضايا إسلامية. والمحبة وقيمة القوة وقيمة السعادة (بوريادي:

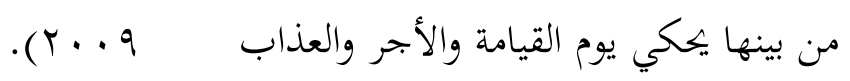
على وجه التحديد أن خرافة كليلة

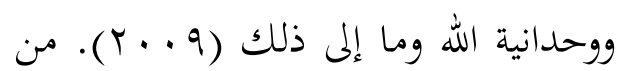

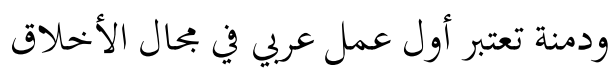
هذا الوصف، يمكن الاستنتاج أن وجود لأهنا تحتوي على نصائح مختلفة بأساليب منطقية للصور من خلال حوار الحيوانات.

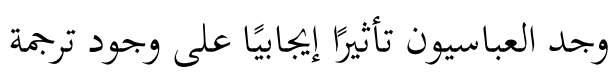
خرافة خلال هذا العصر كان لها تأثير كبير جدًا في بحال التعليم وكان مليئًا بالحكمة الكتاب بحيث أعيد طبعها، كما فعل سهل والقيم الإنسانية العالمية. ابن هارون، أحد أمناء المأمون عند كتابة لمابل كتاب ثعلة وعرفة الذي فقد (بوريادي:

$$
\text { . ( T. . } 9
$$

قال ابن المقفع، إذا كان هناك من استمع إلى الخرافات لكنه لا يجعلها قدوة إدات هن ووسائط للتأمل الذاتي، فهو مثل شخص إن لئل نائم وهناك لص يحاول دخول منزله بتسلق جدران المنزل. لم يستيقظ، لكنه علم أن لصًا 
الكلاسيكية. وهذه بسبب حب الخلفاء العباسيين لأنواع العلوم أحدها علم الأداب.

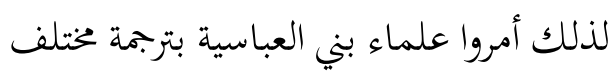
التخصصات، مثل واحد منها هي هذه الخرافة. في حين كان تأثير وجود الخرافات على التعليم خلال العصر العباسي محاولة لتعلم الأخلاق للمجتمع العباسي.

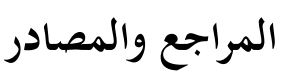

كميجة، ساسي. (11) حكاية الخخرفة على لسان الحيوان /بن

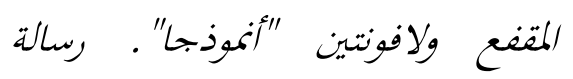
الماجيستير قسم اللغة العربية وآداجا كلية الآداب واللغات جامعة تلمسان.

Djajasudarma, T. Fatimah, (2006). Metode Linguistik Ancangan Metode Penelitian dan Kajian. Cetakan Kedua. Bandung: PT Refika Aditama.

Fatin, Idhoofiyatul, Sofi Yunianti, Sandha Soemantri, Fajar Setiawan. (2018). Master Kisikisi UN SMP/ MTs 2019 Sistem UNBK+UNKP. Jakarta: Cmedia.

Harimurti, Shubhi Mahmashony. (2015). "Seni Pada Masa Pemerintahan Dinasti Abbasiyah Tahun 711-950 Masehi”. Dalam Jurnal Kajian Seni, Jurnal UGM,
سيدخل منزله. قال لنفسه: "والله سأتركها بمفردي ولن أهتم بها حتى أرى ما تفعله. لن

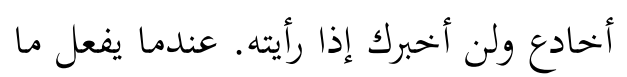
يريد ، عندها سأستيقظ وأتنمر عليه". استمر في البقاء ولم يفعل شيئًا. في هذه الأثناء، استمر اللص في التجول في منزله لفترة طويلة وجمع الأشياء التي وجدها. ثم هزم الرجل بالنعاس ونام مرة أخرى. اللص مريح. جمع ما يريد والسماح له بمغادرة منزل الرجال الذين لا يزالون نائمين على الفور. ثم استيقظ الرجل وعلم أن اللص أخذ أغراضه

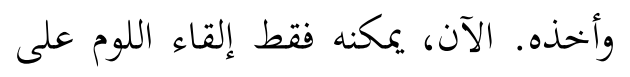
نفسه ويدرك أن معرفته باللص الذي اقتحم منزله لا فائدة منها ولا معنى لها دون اتخاذ إجراء حقيقي. من هذه القصص القليلة، يمكن استنتاج أن تأثير وجود الخرافات خحلال العصر العباسي في عالم التعليم كان حيويًا.

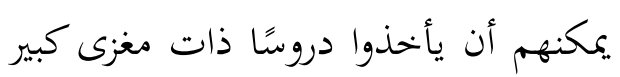
في قصة مسلسل في قصة.

الخحلاصة

من المناقشة أعلاه، يمكننا أن نخلص

إلى استنتاج مفاده أن النموذج المفضل خحلال العصر العباسي كان خرافة الترجمة 
Yogyakarta, Vol. 01, No. 02. Hal. 194-204.

Hitti, Philip K. (2006). History of The Arabs. Penerjemah: R. Cecep Lukman Yasin dan Dedi Slamet Riyadi. Jakarta: PT Serambi Ilmu Semesta.

Https://rumus.co.id. Fabel-

Pengertian, Ciri-ciri, Jenis-jenis, dan Contoh. Didownload Senin 20 April 2020 pada pukul 09:38 WIB.

Kirana, Annisa Candra. (2016). "Perkembangan Puisi Arab Pada Masa Dinasti Abbasiyah". Dalam Skripsi Jurusan Sastra Arab Fakultas Ilmu Pengetahuan Budaya Universitas Indonesia, Depok.

Puriyadi. (2009). Nilai Etika Dalam Kalilah Wa Dimnah Karya Ibn alMuqaffa'. Jurnal Ilmu Ushuluddin, UIN Antasari. Vol. 09, No. 1, Edisi Januari, Hal. 1-23. Safitri. (2015). "Kemajuan Umat Islam Di Masa Bani Abbasiyah Studi Kasus: Kemajuan di Bidang Keilmuan Di Masa Harun Al Rasyid. Skripsi Jurusan Sejarah dan Kebudayaan Islam Fakultas Adab dan Humaniora UIN Syarif Hidayatullah, Jakarta.

Setiawan, Rendy. (2017). "Baitul Hikmah Bukti Majunya Islam di Bidang Ilmu Pengetahuan". https://minanews.net.

Didownload Senin 20 April 2020 pada pukul 06:44 WIB.

Sugiyono. 2008. Metode Penelitian Pendidikan Pendekatan Kuantitatif, Kualitatif, R\&D. Bandung: Alfabeta, 